\title{
Early history of in vitro fertilization
}

\author{
Barry D. Bavister \\ Department of Biological Sciences, University of New Orleans, and the Audubon Center for \\ Research of Endangered Species, New Orleans, LA 70148, USA
}

\begin{abstract}
Although in vitro fertilization (IVF) is used widely for a variety of purposes, it is often not appreciated how this technology was developed. A large number of experiments beginning in 1878 contributed to the first successful reports of IVF over 75 years later. The discovery of sperm capacitation in 1951 was central to the development of IVF technology, and it was rapidly followed by the first convincing reports of IVF in several species. The ability to fertilize oocytes in vitro has allowed major advances to be made into understanding the mechanisms involved in fertilization and early development, and IVF now supports reproductive biotechnology in animals and in humans. This article is a historical review of key experiments that helped to provide the basis for present day IVF procedures, placed into context with current practice.
\end{abstract}

In vitro fertilization (IVF) is a well-established technology with a variety of applications in basic and applied sciences. The technology supports the production of embryos used for research investigations, for treating human infertility, for enhancing the productivity of food animals, and for conservation of endangered mammals. For most species, IVF protocols are available that routinely provide high or at least acceptable proportions of fertilized ova, leading to the production of viable embryos that can develop into normal offspring after transfer to recipient females. In view of the extraordinary advances in IVF technology during the past few decades, and its current role in many areas of basic and applied science, it is easy to ignore the origins of IVF in basic research studies conducted as long ago as 1878, and to overlook the enormous significance of the discovery of sperm capacitation. For example, it is not well recognized that the basis for the first documented human IVF success in 1969 can be traced back to two groundbreaking articles with hamster gametes (Yanagimachi and Chang, 1963, 1964); these studies were the first to report mammalian IVF using spermatozoa capacitated in vitro. An earlier study by Chang (1959) showing that rabbit eggs fertilized in vitro could develop into normal young was also crucial to the acceptance starting 20 years later of human IVF as a clinical infertility treatment. Moreover, many of the key studies underlying the development of IVF were published before electronic databases such as Medline began cataloguing articles, and some reports appeared in sources not represented in these databases.

The present review attempts to describe the contributions to IVF made by numerous pioneering scientists up to 1971 and to illustrate some of the difficulties encountered in this

Email: bbaviste@uno.edu research. This cutoff date is used because most of the review was written as the Introduction of the author's unpublished PhD dissertation (Bavister, 1971). That Introduction has now been expanded and updated to recognize the current status and practice of IVF. The 1950s and 1960s were the 'golden age' of IVF, when, after the discovery of sperm capacitation, the first convincing successes were reported for several important species including the rabbit, mouse, hamster, rat and human. It seems timely to present the earliest work to remind present-day scientists how much is owed to the IVF pioneers, and how much the routine, protocol-driven IVF technology relies heavily on the information they provided.

The focus of this review is on spermatozoa and the changes they need to undergo before becoming able to fertilize an oocyte. It does not address the complexity of changes undergone by oocytes as a consequence of sperm penetration, in part because the author's early research focus was on sperm capacitation, and in part because so little was known before 1971 about parallel events occurring in mammalian oocytes during fertilization. Since the advent of IVF technology, many detailed reviews and articles have been published on the responses of oocytes to activation by spermatozoa (for example, Yanagimachi, 1994; Fissore et al., 1998; Hewitson et al., 2000). The present review does not address embryonic development subsequent to IVF, about which a very large number of articles have also been published (see Bavister, 1995; Niemann and Wrenzycki, 2000; Khosla et al., 2001). The cited publication list is not exhaustive but includes those articles that were considered by the author in 1971 to be most relevant to sperm capacitation and IVF up to that time, as well as some representative contemporary references to illustrate how the field has progressed in theory and in practice since then. 


\section{Early in vitro fertilization studies}

In spite of intensive research efforts conducted since the latter half of the 19th Century, by 1971, knowledge of the physiology, biochemistry and morphology of mammalian fertilization and embryonic development was still sparse and inadequate, compared with the wealth of knowledge about that of amphibians and sea-urchins. The progress of research was hindered by the internal site of mammalian fertilization, which means that events involved in fertilization of mammalian eggs and early embryonic development cannot be investigated readily in their natural environment. Therefore, information concerning the relationship between the egg or the developing embryo and the immediate maternal environment is difficult to obtain. A potentially useful technique is to recover fertilized eggs or early embryos from the female reproductive tract, and to study their subsequent development in vitro. This approach has been used widely, but provides little information about the preceding events in vivo. Moreover, the timing of ovulation and of fertilization in vivo cannot be predicted accurately, which particularly restricts the investigation of rapidly occurring events, such as the penetration of spermatozoa through the egg investments and the changes undergone by the gametes during the early stages of fertilization.

Information can be derived much more readily from the study of eggs that are fertilized and then develop in vitro. Not only can the process of fertilization be closely observed, but also factors contributing to normal and abnormal fertilization and development can be examined. The progress of fertilization or embryogenesis can be frequently, if not continuously, observed and the conditions of culture can be varied to examine their effects on development. Thus, a wealth of information is available from studies in vitro, given the technical ability to accomplish them.

\section{Early attempts to fertilize mammalian eggs in vitro}

Between 1878 and 1953, numerous attempts were made to fertilize mammalian eggs in vitro. Although many reports were published claiming successful results, in the light of modern knowledge, most of these claims seem unjustified. Fertilization is a progressive, continuous process, beginning with the penetration of an egg by a spermatozoon, which results in the extrusion of the second polar body from the egg. This extrusion is followed by the formation, growth and juxtaposition of the pronuclei, and the process of fertilization culminates in the union of maternal and paternal chromosomes (syngamy), restoring the diploid state. Some authors still refer to the timing of specific events as occurring 'post-fertilization' when they actually mean 'post-insemination' of the oocytes. For example, erroneous and contradictory statements such as 'pronuclear formation begins [several] hours post-fertilisation' have been published.

Several early investigators attempted IVF using ovarian oocytes that were probably not mature enough to undergo fertilization (Schenk, 1878; Pincus and Enzmann, 1935; Pincus, 1939). Other workers were aware of this problem. Rock and Menkin (1944) and Menkin and Rock (1948) cultured human ovarian oocytes for a time before insemination but, in retrospect, the time allowed for maturation of oocytes in vitro, which was based on the data of Pincus and Saunders (1939), was probably inadequate, judging from the work of Edwards (1965). Although it is possible that maturation of some oocytes could have been completed within the period during which the spermatozoa and eggs were incubated together, this still does not provide evidence that fertilization was accomplished in vitro.

Most of the criteria used to judge the results of IVF experiments can be misleading: for example, extrusion of the second polar body and development of eggs through the early cleavage stages may also be evoked by parthenogenetic activation, or mimicked by fragmentation. Eggs of the rabbit, the most commonly used species for the earliest IVF experiments, can be activated readily in culture by a variety of stimuli other than sperm penetration (Pincus, 1936, 1939; Thibault, 1949; Chang, 1954). The results of a study by Dauzier and Thibault (1956) indicated that the incidence of parthenogenetic activation of rabbit eggs in culture was increased by the presence of spermatozoa. However, cleavage of unfertilized rabbit eggs in culture was reported to be much less common if the eggs were incubated with scrapings of Fallopian tube mucosa (Smith, 1951). Before the study of Smith (1951), only Schenk (1878) had used reproductive tract mucosa in the culture system. Parthenogenetic activation may be induced by cooling the eggs of some species; for example, the rat eggs used by Long (1912) are particularly susceptible in this respect (Austin, $1956 a, b)$. With the exception of Smith (1951), none of the investigators in this field from Schenk (1878) to Shettles (1953) maintained the eggs at $37^{\circ} \mathrm{C}$ to preclude the possibility of cooling-induced activation. It is also possible that incubating eggs for prolonged periods at less than normal body temperature limited or even destroyed their ability to undergo normal fertilization and development.

As the eggs of some mammalian species may undergo parthenogenetic development in culture, the occurrence of apparently normal activation and cleavage of eggs in vitro is insufficient evidence for fertilization. The demonstration of sperm penetration into eggs in vitro, together with the formation of pronuclei and the second polar body, provides more convincing evidence for fertilization. No studies conducted before 1954 seem to have achieved this.

In some of the early experiments in rabbits, sperm heads that were apparently within the egg cytoplasm may have been superimposed during histological preparation (Moricard and Bossu, 1949; Moricard, 1950). Shettles (1953) reported that perivitelline spermatozoa were found in five human eggs that were inseminated in vitro, but the photographic evidence supporting this claim is by no means convincing and, in some cases, there appear to be breaks in the continuity of the zona pellucida through which spermatozoa might have gained entry. Smith (1951) claimed that 10 of 35 
tubal rabbit eggs were penetrated by spermatozoa after finding sperm nuclei or developing male pronuclei in the egg cytoplasm; however, photographic evidence was not submitted to support this claim. One additional egg cleaved, but no sperm penetration was observed, and so parthenogenetic activation cannot be excluded.

The evidence for achievement of fertilization in vitro presented by Pincus and Enzmann (1934) appears more convincing. These workers obtained offspring after incubating rabbit eggs and spermatozoa in vitro and transferring the eggs, after washing them, to a recipient doe. However, these eggs may have been fertilized after transfer to the oviduct of the recipient animal. The removal of all adherent spermatozoa from freshly ovulated, cumulus-enclosed eggs is difficult (Chang, 1968), so it is likely that some spermatozoa escape the washing procedure and can be transferred into the oviducts along with the eggs. In the study by Pincus and Enzmann (1934), the interval between the start of gamete co-incubation in vitro and transfer of the eggs was only $20 \mathrm{~min}$, so spermatozoa attached to oocytes were probably still capable of effecting fertilization in vivo. This criticism also applies to the experiments of Venge (1953), in which two litters of rabbits were obtained. In these experiments, the time interval between insemination of eggs in vitro and their transfer to recipients $(3.5 \mathrm{~h}$ ) was still insufficient to exclude the possibility of in vivo fertilization. This inherent problem is highlighted by the later adoption of this procedure as a treatment for infertile women, in which spermatozoa and eggs are mixed together in vitro and then transferred rapidly into the oviduct (Asch et al., 1986). The high pregnancy success rates achieved with this 'gamete intra-Fallopian transfer' procedure indicate that the early claims for IVF success using this approach in animals were unwarranted.

In retrospect, it seems that most of the claims to have fertilized mammalian eggs in vitro made before 1954 were inadequately substantiated or were probably based on misinterpreted results. This conclusion is not surprising in view of the many experimental pitfalls discussed above; however, the possibility that IVF was obtained in some cases cannot be ruled out.

\section{Discovery of capacitation}

The probable cause of the lack of success of most of the early IVF experiments emerged with a major discovery by Austin (1951) and Chang (1951). These workers found that if spermatozoa were introduced into the oviducts of rabbits shortly after the predicted time of ovulation, very few eggs were fertilized, despite rabbit eggs remaining fertilizable for up to $8 \mathrm{~h}$ after ovulation (Chang, 1952; Adams and Chang, 1962a). In contrast, a high proportion of eggs was fertilized if oviductal insemination was performed several hours before ovulation. Observations carried out on rats showed that when spermatozoa were deposited directly into the ovarian capsule after ovulation, no penetrated eggs were recovered until about $4 \mathrm{~h}$ later, after which the number of eggs undergoing fertilization increased rapidly (Austin, 1951). This significant delay before egg penetration was not an artifact of experimental interference, as in oestrous rats permitted to mate naturally but only after ovulation had occurred, penetration of eggs still did not start for about $2 \mathrm{~h}$, even though spermatozoa rapidly reached the oviducts (Austin, 1952).

Both Austin and Chang postulated that the spermatozoa of some mammalian species need to reside for some time within the female reproductive tract before acquiring the capacity to penetrate eggs, and Austin (1951) coined the term 'capacitation' to refer to the change that spermatozoa undergo during this time. The need for rabbit spermatozoa to undergo capacitation almost certainly contributed to the failure of most attempts made before 1954 to achieve IVF in this species. In these experiments, spermatozoa were invariably recovered directly from the male reproductive tract. Today, it is known that spermatozoa from many species can be capacitated in vitro, but in several key animals, including rabbits, the spermatozoa must be treated in special ways before they can take part in fertilization (see section on 'Mechanisms of capacitation and the acrosome reaction').

\section{Fertilization of eggs in vitro after the discovery of capacitation}

Renewed interest in the fertilization of mammalian eggs in vitro followed the discovery of capacitation. Within a few years, rabbit eggs were fertilized in vitro for the first time, using spermatozoa recovered from the uterus (Dauzier et al., 1954; Thibault et al., 1954; Dauzier and Thibault, 1956). Many other workers confirmed these results, at first using spermatozoa capacitated in vivo (Brackett and Williams, 1965, 1968; Brackett, 1968). However, almost 20 years elapsed after the first rabbit IVF before this was repeated using spermatozoa capacitated in vitro (Ogawa et al., 1972; Brackett and Oliphant, 1975; Brackett et al., 1978; Hosoi et al., 1981).

In a landmark study, Chang (1959) showed that in vitrofertilized eggs could develop normally. After transfer of IVF rabbit eggs to foster mothers, living young were born that resembled their parents in coat colour. The observation that eggs showed morphological signs of fertilization (including cleavage) before transfer (Chang, 1959) precludes the possibility that eggs were simply fertilized in vivo by attached spermatozoa, which was not excluded in earlier studies. Numerous other studies duplicated these results (for example, Thibault and Dauzier, 1961; Brackett, 1969; Brackett and Oliphant, 1975).

During the 'golden age' of IVF, good morphological evidence was provided for success in several other important mammals. Technical aspects of IVF in a wide variety of species are thoroughly described and evaluated by Rogers (1978). Sperm penetration, emission of the second polar body and formation of pronuclei were all seen in golden (Syrian) and Chinese hamster eggs inseminated in 
vitro (Yanagimachi and Chang, 1963, 1964; Barros and Austin, 1967; Pickworth and Chang, 1969). In one study, $45 \%$ of golden hamster eggs inseminated in vitro were fertilized and cleaved to the two-cell stage in culture (Yanagimachi and Chang, 1964). However, in spite of intensive efforts, none of these eggs developed further in vitro as a result of the 'two-cell block', which held up progress with cultured hamster embryos for 25 years after the landmark articles of Yanagimachi and Chang (1963, 1964) (Schini and Bavister, 1988), and it was not until 1992 that the first IVF hamster pups were born (Barnett and Bavister, 1992).

Whittingham (1968), Iwamatsu and Chang (1969, 1970) and Toyoda et al. (1971a,b) reported IVF of mouse eggs using spermatozoa capacitated in vitro. Whittingham (1968) transferred in vitro-fertilized mouse eggs at the twocell stage to recipient mice, and subsequently recovered normal 17-day-old fetuses that genetically resembled their parents. Cross and Brinster (1970) and Mukherjee and Cohen (1970) confirmed this result with mouse eggs that were both matured and fertilized in vitro.

Toyoda and Chang (1968) were able to fertilize rat eggs in vitro, but only after removal of the zona pellucida. Miyamoto and Chang (1973) reported IVF of intact eggs with rat spermatozoa recovered from the uterus of mated females. Subsequently, in vitro capacitation and fertilization in the rat were accomplished by Toyoda and Chang $(1974 a, b)$

Thibault and Dauzier (1961) reported the fertilization of a few sheep eggs and one pig egg in vitro, but many years elapsed before protocols were devised that supported consistent IVF results in these species and offspring were produced (Bondioli and Wright, 1980; Crozet et al., 1987; Slavik and Fulka, 1991; Abeydeera, 2002).

Cat eggs that were inseminated in vitro with spermatozoa incubated in utero cleaved as far as the 16-cell stage (Hamner et al., 1970). However, the first IVF using spermatozoa capacitated in vitro was not reported until 1977 (Bowen, 1977). IVF using spermatozoa capacitated in vitro has been used more recently by several laboratories to produce embryos for conservation of endangered species (Roth et al., 1994a,b; Pope et al., 2000, 2001).

Guinea-pig eggs were fertilized in vitro using epididymal spermatozoa (Yanagimachi, 1972), although it took up to $18 \mathrm{~h}$ before penetration began. It was later shown that guinea-pig sperm capacitation is retarded by glucose and by magnesium ions; in their absence, the time required for sperm capacitation was shortened to only 2-3 h (Rogers and Yanagimachi, 1975, 1976; Rogers et al., 1979).

Fertilization of dog eggs in vitro was reported by Mahi and Yanagimachi (1976) and the time needed for capacitation of canine spermatozoa in vitro was estimated at $7 \mathrm{~h}$. It was reported by Rogers (1978) that dog spermatozoa could become capacitated and undergo acrosome reactions in the absence of any egg or cumulus factors.

Fertilization of human eggs in vitro was first convincingly achieved in 1969, as evidenced by sperm penetration, polar body emission and formation of pronuclei (Bavister et al., 1969; Edwards et al., 1969). This advance was based on modifications of the culture medium protocol used by Yanagimachi and Chang $(1963,1964)$, so it may be claimed that hamster IVF paved the way for human IVF (Bavister, 2002). In a classic understatement, Edwards commented that 'Human oocytes have been matured and fertilized by spermatozoa in vitro. There may be certain clinical and scientific uses for human eggs fertilized by this procedure.' (Edwards et al., 1969). Some IVF human eggs were capable of undergoing apparently normal cleavage and differentiation in culture (Edwards et al., 1970; Steptoe et al., 1971). However, the first human birth from an IVF embryo was not reported until 1978 (Steptoe and Edwards, 1978), apparently because the ovarian stimulation regimens may have interfered with establishment of pregnancy or produced incompetent eggs. Since 1978, the clinical applications of human IVF have become widespread, so that probably more than a million IVF babies have been born worldwide. Originally proposed by Edwards and Steptoe as a treatment for infertility in women, human IVF and its derivative intracytoplasmic sperm injection (ICSI) are now used to treat male infertility, and even azoospermia.

Progress with IVF in non-human primates was slower than it was in humans. Successful IVF in the squirrel monkey was first reported by Gould et al. (1973) and by Kuehl and Dukelow (1975). However, in these studies, the presence of fertilizing sperm tails in the eggs was not shown, and the developmental ability of the IVF eggs was very low. Unequivocal evidence for IVF in rhesus macaques was reported by Bavister et al. (1983), who showed the presence of sperm tails in eggs, and considerable postfertilization development. Stimulation of spermatozoa with caffeine and cyclic AMP was essential for supporting sperm fertilizing ability (Boatman and Bavister, 1984). Nonhuman primate IVF, mostly using macaque species, is now used by several laboratories world-wide to investigate primate fertilization and early embryonic development. In all cases, spermatozoa capacitated in vitro have been used. There appears to be only one report of IVF in chimpanzees (Gould, 1983). Oocytes were inseminated in vitro using Ham's F10 medium supplemented with serum and caffeine-cyclic AMP but it is not known whether these chemical stimulators are essential for sperm capacitation in chimpanzees. Of 18 oocytes that were mature at the time of collection, 11 were fertilized in vitro and five cleaved to about the three-cell stage.

\section{Relationship between capacitation and the acrosome reaction}

In most of the IVF studies carried out between 1954 and 1971, spermatozoa were either capacitated in vivo before insemination of the eggs, or it could be demonstrated or inferred from the timing of egg penetration that capacitation was required and had occurred in vitro. The spermatozoa of 
mammals must undergo an acrosomal change called the acrosome reaction before penetration (Yanagimachi, 1994). The acrosome reaction was first demonstrated by Austin and Bishop (1958a,b), who used the novel technology of phase-contrast microscopy to discover that the spermatozoa of guinea-pigs, hamsters and Libyan jirds lost their acrosomes as they penetrated the zona pellucida. Later studies using the electron microscope, first with hamster spermatozoa, showed that this loss is restricted to the outer acrosomal membrane and acrosomal contents (Barros et al., 1967; Franklin et al., 1970). The acrosome reaction was found also to be prerequisite for fertilization in rabbits (Bedford, 1967, 1968), rats (Pikó and Tyler, 1964) and pigs (Dickmann and Dziuk, 1964), and bull spermatozoa were also found to undergo an acrosome reaction (Blom, 1963; Saacke and Almquist, 1964; see also Colwin and Colwin, 1967). In light of all this evidence, it was assumed that the acrosome reaction is a common characteristic of mammalian spermatozoa (Yanagimachi, 1994).

At first, there was considerable confusion over nomenclature concerning the changes that spermatozoa undergo before penetrating eggs. Austin and Bishop (1958b) suggested that the acrosome reaction constituted a part of the process of capacitation, whereas Yanagimachi (1969a) considered that the acrosome reaction '... must represent the final phase of sperm capacitation'. However, an acrosome reaction that is basically similar to that undergone by mammalian spermatozoa is exhibited by the spermatozoa of many marine invertebrates, including annelids, molluscs and echinoderms, and by spermatozoa of two other vertebrate groups, lampreys and sturgeons (Dan, 1956, 1967; Colwin and Colwin, 1965, 1967). However, capacitation seems peculiar to mammals. In agreement with the views of Bedford (1968) and Pikó (1969), it seems most appropriate to consider that capacitation is a discrete physiological change that enables mature spermatozoa to respond to appropriate stimuli, and thereby to undergo the acrosome reaction. This is the most logical way to view the changes undergone by spermatozoa within the female reproductive tract. Although the acrosome reaction is a fundamental change in structure undergone by the spermatozoa of animals from widely diverse groups, capacitation may be regarded as a process that has evolved to suit some peculiar feature of mammalian reproduction (for a review, see Pikó, 1969). Most likely, capacitation represents a conditioning process that prepares spermatozoa to undergo acrosome reactions very rapidly once they are exposed to mature oocytes within the oviduct. However, in the absence of appropriate stimuli (that is, zona pellucida or cumulus oophorus components), most capacitated spermatozoa would not automatically undergo acrosome reactions in vivo, thus maintaining them in a stable configuration for several hours, even days, before the arrival of ovulated oocytes. Thus, capacitation may be viewed as a mechanism for coordinating acrosome reactions with the availability of unfertilized oocytes, which has evolved together with internal fertilization. This view is consistent with the apparent lack of capacitation in animals exhibiting external fertilization, in which spermatozoa are deposited in direct proximity to the oocytes, undergo acrosome reactions almost immediately, and have very short functional lifespans, usually encompassing only a few minutes. In contrast, it appears that mammalian spermatozoa may be sustained within the female reproductive tract without losing their fertility for many hours or even days.

\section{Capacitation in different species}

The evidence derived from early studies of a need for capacitation in mammals was necessarily circumstantial, being largely derived from the timing of penetration of eggs in vivo (Austin, 1951; Chang, 1951, 1969; Bedford, 1970a) or in vitro (Yanagimachi and Chang, 1963, 1964). Nevertheless, the sheer volume of this evidence in a wide variety of mammals (Austin, 1969; Yanagimachi, 1994) provided strong support for the concept of capacitation, even though very little was known about its mechanism.

In rabbits, a large mass of information was gathered concerning the need for spermatozoa to undergo capacitation before penetrating eggs (for a review, see Chang, 1969); however, much of these data were conflicting and confusing with regard to the conditions needed for capacitation. Most of the information related to capacitation in the rabbit uterus, but the oviduct was shown to be the major site of capacitation (Bedford, 1970a,b), although capacitation was accomplished in the shortest time (5-6 h) when spermatozoa passed from the uterus to the oviduct (Chang, 1955; Adams and Chang, 1962b). Bedford (1970a) provides the best discussion on the state of knowledge regarding capacitation in the rabbit and in other animals during the 'golden age' of IVF.

Further studies on the time relationships of fertilization in vivo in rats (Austin, 1952; Noyes, 1953; Austin and Braden, 1954) confirmed the original observation (Austin, 1951) that capacitation was required in this species. In golden hamsters, the need for capacitation was firmly established from the timing of fertilization in vivo (Strauss, 1956; Chang and Sheaffer, 1957; Yanagimachi, 1966; Hunter, 1969), together with IVF data (Yanagimachi and Chang, 1963, 1964; Yanagimachi, 1966, 1969a; Barros and Austin, 1967; Barros, 1968). In early IVF studies, high percentages of golden hamster eggs were fertilized in vitro with epididymal spermatozoa that had not been exposed to the female reproductive tract (Yanagimachi and Chang, 1963, 1964; Barros and Austin, 1967; Barros, 1968). Barros (1968) reported a delay of about $3 \mathrm{~h}$ before egg penetration took place in vitro. This delay was reduced to less than $30 \mathrm{~min}$ by preincubating spermatozoa with oviductal fluid containing ova in cumulus. These results were interpreted as indicating that golden hamster spermatozoa can be capacitated in vitro by incubation with cumulus oophorus fluids. Barros and Austin (1967) showed that hamster follicular eggs could be fertilized in vitro, and that follicular contents could induce the acrosome reaction in hamster spermatozoa. 
These workers concluded that hamster epididymal spermatozoa could be capacitated in vitro, in the absence of any contribution from the female reproductive tract, as reported by Yanagimachi and Chang (1963, 1964). Later work by Yanagimachi (1969a) amply supported this conclusion. It became accepted that capacitation of hamster spermatozoa is a change undergone normally within the female reproductive tract, but which may occur in vitro under special conditions. Follicular fluid is able to provide these conditions (Yanagimachi, 1969a,b), and the presence of this fluid was essential in these early studies to allow hamster spermatozoa to undergo the acrosome reaction and penetrate eggs in vitro. Alternatively, follicular fluid can be replaced by serum albumin (Bavister, 1969) or by the fluid component of the cumulus oophorus (Bavister, 1982). Although the need for capacitation was firmly established by 1971 in rabbits, rats and golden hamsters, the demonstration of capacitation in other mammalian species was less well documented. After their introduction into the tubal ampulla via the ostium, ferret spermatozoa did not penetrate eggs within the oviduct until $3.5 \mathrm{~h}$ had elapsed (Chang and Yanagimachi, 1963). This delay presumably represents the time needed for capacitation of ferret spermatozoa in the oviduct. The time relationships of hybrid fertilization of rabbit eggs by snowshoe hare spermatozoa indicated that capacitation of these spermatozoa was necessary and took $6-10 \mathrm{~h}$ in the rabbit oviduct; this timing is very similar to that for oviductal capacitation of rabbit spermatozoa (Chang et al., 1971). In a study of the time relationships of fertilization in the Mongolian gerbil and in the deer mouse, animals were artificially inseminated after the time of induced ovulation (Marston and Chang, 1966). The time interval between insemination and the earliest recovery of penetrated eggs was about $4 \mathrm{~h}$ for the gerbil and $3 \mathrm{~h}$ for the deer mouse. These data were consistent with the idea that capacitation occurs in both of these species. The time needed for IVF of a few Chinese hamster eggs by epididymal spermatozoa was approximately the same as that required for golden hamster eggs (Pickworth and Chang, 1969).

In mice, the time relationships for fertilization in vivo indicated that either capacitation occurred within a very short time (about $1 \mathrm{~h}$ ) or else capacitation was not required in this species (Braden and Austin, 1954). However, Iwamatsu and Chang (1970) subsequently reported that although $1 \mathrm{~h}$ or more was needed for untreated epididymal spermatozoa to penetrate eggs in vitro, spermatozoa that had been preincubated in heterologous follicular fluid were able to effect penetration in only $20 \mathrm{~min}$. This result was interpreted as indicating that capacitation of mouse spermatozoa was required, and occurred within about $1 \mathrm{~h}$. This timing is consistent with later estimates made using a quantitative fluorescence assay of between 30 and 90 min for mouse sperm capacitation (Ward and Storey, 1984).

The IVF experiments of Hamner et al. (1970) indicated that cat spermatozoa require about $0.5-2.0 \mathrm{~h}$ of incubation in utero for capacitation to occur. This supposition has been amply confirmed using IVF with spermatozoa capacitated in vitro in domestic and endangered felids (Andrews et al., 1992; Roth et al., 1994a,b; Pope et al., 2000, 2001). The results of several early studies indicated a need for capacitation of ram spermatozoa. When ejaculated spermatozoa were introduced into the oviducts of ewes shortly after ovulation, no penetrated eggs were recovered until 3-5 h later. After incubation for several hours in the ligated uterus, spermatozoa were able to penetrate eggs 1.5-2.0 h after deposition into the oviduct (R. Moore, C. Polge and L. Rowson, unpublished). However, Mattner (1963) found that tubally inseminated spermatozoa needed only $1.5 \mathrm{~h}$ to penetrate eggs even without prior incubation in utero. Dauzier and Thibault (1959) were able to fertilize sheep eggs in vitro with spermatozoa recovered from the uterus of a mated ewe, but not with ejaculated spermatozoa. In retrospect, this failure was probably due to unsuitable culture conditions for supporting capacitation in vitro, because several authors have since reported successful IVF in sheep using spermatozoa taken directly from the male reproductive tract (Bondioli and Wright, 1980; Crozet et al., 1987; Slavik and Fulka, 1991) and the need for ovine sperm capacitation is now well established.

The few critical observations available on the timing of fertilization in the pig up until 1971 were consistent with a need for capacitation in this species. Boar spermatozoa introduced into the oviducts soon after ovulation did not penetrate eggs until 4 or 5 h later (Polge, 1969). Hunter and Dziuk (1968) found that only 2 h elapsed between the time of artificial insemination and the beginning of egg penetration. This delay presumably represents the time needed for capacitation and the acrosome reaction, as the time needed for sperm transport to the oviducts is only $15 \mathrm{~min}$ in this species (First et al., 1968). In view of the observation made by Polge (1969), capacitation does not appear to proceed optimally in the oviduct alone. Although production of viable pig embryos by IVF is now quite routine using in vitro-matured (IVM) oocytes, the problem of polyspermic fertilization remains and the aetiology of this defect is not understood (Abeydeera, 2002). Moreover, embryos produced by IVM and IVF have low average developmental competence in vitro, which may also be the result of inadequate maturation of the egg cytoplasm (Niemann, 2001).

The early observations of Ericsson (1967a) and Lauderdale and Ericsson (1970) indicated that capacitation was necessary for bull spermatozoa, and an unpublished result of Edwards (quoted by Austin, 1969), concerning the time needed for the penetration of cow eggs in vitro, supported this suggestion. However, Mahajan and Menge (1966) were unable to demonstrate any advantage of uterineincubated bull spermatozoa over control spermatozoa in terms of ability to fertilize eggs in vivo. Thus, the need for capacitation of bull spermatozoa was not convincingly demonstrated by these early studies. However, it has since been shown unequivocally that bull spermatozoa, like those of all other mammals studied, do require capacitation, 
which can be achieved in vitro under special conditions (see 'Mechanisms of capacitation and acrosome reaction'). The technique of IVF in cattle (Bos taurus) is among the most successful of all species; $40 \%$ or more of inseminated IVM oocytes can develop into blastocysts, and many calves have been born that were derived from these processes (Brackett et al., 1978; Hasler, 1998).

It was uncertain from the early studies whether primate spermatozoa require capacitation. In humans, the IVF experiments of Edwards et al. (1969) showed a delay of about $7 \mathrm{~h}$ between insemination of the eggs and the beginning of penetration; it seemed likely that this delay reflected a need for sperm capacitation. Unfortunately, insufficient material was available at that time to investigate this possibility more thoroughly. The observations of Marston and Kelly (1968) on the time relationships of fertilization in rhesus monkeys did not allow any conclusions to be drawn regarding the need for capacitation in this species. Now, it is clear that primate spermatozoa do need a period of capacitation. Macaque monkey spermatozoa require treatment with chemical mediators to acquire the capacity to undergo acrosome reactions and to bind and then penetrate the zona pellucida (Boatman and Bavister, 1984). This finding is curious because human spermatozoa require only washing and incubation for a few hours in a culture medium, without any specific chemical treatments, to become capable of fertilizing oocytes in vitro (Mortimer, 1994, 2000).

It has also been claimed that some amphibian spermatozoa undergo capacitation. Shivers and James (1970) showed that untreated frog spermatozoa penetrated very few eggs from which the jelly-coats had been removed; however, spermatozoa that had been preincubated with uterine eggs (that is, with intact jelly-coats) were subsequently able to penetrate a high proportion of de-jellied eggs. These workers inferred a need for capacitation of frog spermatozoa. In addition, Wolf and Hedrick (1971) found that Xenopus laevis spermatozoa needed to react with jellycoat materials before penetrating eggs, and concluded that capacitation was required. However, these studies do not indicate whether the short time-interval between insemination and penetration of eggs (5 min in frogs; $20-30 \mathrm{~min}$ in Xenopus) includes a period of capacitation, similar to that in mammals, or whether it represents only the time needed for an acrosome reaction to take place. If capacitation does not occur, the prolonged time needed for acrosome reactions in amphibian spermatozoa may represent an interesting evolutionary intermediate between the spermatozoa of some invertebrates in which the acrosome reaction occurs immediately on contact with the egg capsule (Dan, 1956; Colwin and Colwin, 1967), and the spermatozoa of mammals, which need a period of capacitation usually requiring several hours.

It can be concluded that capacitation of spermatozoa is peculiar to mammalian reproduction and is a prerequisite for fertilization. Capacitation has not been found to be unnecessary in any mammal so far investigated, although it may occur very rapidly in some species (for example, mice), so it may be assumed that capacitation is a universal phenomenon in mammals.

\section{Hyperactivated motility of spermatozoa}

Concomitant with the completion of capacitation in vitro, golden hamster spermatozoa exhibit 'whiplash' flagellar activity that can easily be observed under a phasecontrast microscope (Yanagimachi, 1970). After 3-4 h incubation under capacitating culture conditions, most motile spermatozoa show this vigorous 'hyperactivated' pattern of activity characterized by high amplitude flagellar bending, whereas in the early IVF studies, spermatozoa incubated under non-capacitating conditions never showed activation. Hyperactivated sperm motility was also observed through the wall of the oviductal ampulla in mated hamsters and mice, and hyperactivated spermatozoa have been flushed from ampullae of several other species near the time of fertilization (Katz and Yanagimachi, 1980, 1994; Demott and Suarez, 1992). These observations indicate that this change in flagellar activity is a natural event in capacitation that is involved in sperm penetration through the egg investments (Yanagimachi, 1970; Katz et al., 1989; Suarez et al., 1991) and is perhaps also necessary for spermatozoa to reach the site of fertilization (Shalgi et al., 1992). Hyperactivated motility of spermatozoa incubated under capacitating conditions also occurs in many other species (Yanagimachi, 1994). Although the precise functional significance of hyperactivation is still not clear, this marked change in motility could be a useful indicator of capacitation in individual spermatozoa. However, hyperactivation can also occur under noncapacitating conditions. When golden hamster spermatozoa are incubated in the absence of serum albumin and cumulus oophorus factors, after 3-4 h they begin to exhibit hyperactivated motility that appears identical to that seen under capacitating conditions. However, these spermatozoa incubated in the absence of serum albumin and cumulus oophorus factors are not capacitated, do not undergo spontaneous acrosome reactions and cannot fertilize oocytes (Bavister, 1981, 1982).

\section{Mechanisms of capacitation and the acrosome reaction}

It seems surprising that research into the nature of capacitation proceeded very slowly for 20 years after its discovery (1951-1971). Some of the early developments in this research were reviewed by Austin $(1961,1967)$ and later developments were reviewed by Yanagimachi (1994). A major obstacle to progress was, and remains, the absence of a suitable means of determining whether individual spermatozoa have been capacitated, other than by observing their ability to penetrate eggs. In a sperm suspension incubated in vitro, there will be a heterogeneous population of living and dead, motile and non-motile, 
capacitated and non-capacitated spermatozoa, and the relative proportions of all these will change over time. This fluctuating heterogeneity of sperm suspensions in vitro makes biochemical studies into the mechanism of capacitation difficult, and it may be unwise to ascribe particular chemical or physical properties found in the population as a whole to those few spermatozoa capable of fertilizing eggs. Bavister (1986) suggested that '...characteristics evaluated in a large sperm population may be more representative of nonfertile than of capacitated spermatozoa'.

In spite of this concern, a large amount of information has been gathered on the changes undergone by spermatozoa during capacitation in vivo and in vitro. The results of several early studies indicated that, at least in rabbit spermatozoa, no readily detectable morphological change occurs during capacitation (Adams and Chang, 1962b; Austin, 1963; Bedford, 1963, 1964). A report of progressive elevation or loosening of the rabbit sperm plasma membrane during capacitation (Bernstein, 1966) was unsubstantiated by other workers, and the observations probably resulted from fixation artifacts (Bedford, 1969a,b). Nevertheless, some subtle changes do occur in the surface of spermatozoa during capacitation. Spermatozoa within the uterus of the oestrous rabbit were readily engulfed by leucocytes, but in the pseudopregnant uterus, where little or no capacitation occurs, leucocytes failed to ingest intact motile spermatozoa (Bedford, 1965). In addition, a potent substance found in the seminal plasma of a fertile rabbit merely agglutinated ejaculated or epididymal spermatozoa, but immediately immobilized spermatozoa recovered from the uterus (Bedford, 1970c). Furthermore, the net negative charge was reduced on the surface of rabbit spermatozoa after incubation in the oestrous uterus (Vaidya et al., 1971).

In the early studies, a considerable volume of information was accumulated on the metabolic changes that occur in spermatozoa after incubation in the female reproductive tract, or during incubation in vitro with secretions from the tract (for a review, see Iritani et al., 1969). It is not known to what extent these metabolic changes are involved with capacitation; they may reflect changes in membrane permeability resulting from capacitation, facilitating the exchange of ions and substrates between the spermatozoon and its environment, or they may be merely contemporaneous with capacitation.

It does seem paradoxical that, whereas capacitation of spermatozoa is accepted as being universally required in mammals, methods for supporting this process in vitro differ markedly among species. The mechanism of capacitation, and hence the in vitro conditions for capacitating spermatozoa, might be expected to be very similar across species, but this is clearly not so. Mouse spermatozoa can be capacitated simply by diluting epididymal contents into a suitable culture solution and incubating them for as little as 30 min; guinea-pig spermatozoa can be capacitated in the same way by incubation for 2-3 h (Rogers, 1978). This simple approach also works for human and dog spermatozoa, after removal of seminal plasma by washing or gradient centrifugation (Mahi and Yanagimachi, 1976, 1978; Mortimer, 1994, 2000). Rabbit spermatozoa can also be capacitated in vitro by simply washing and incubation, but there must be a second wash step after an initial short period of incubation, probably to eliminate soluble seminal plasma factors from the culture environment (Brackett and Oliphant, 1975; Hosoi et al., 1982). In contrast to human spermatozoa, in another primate genus, the macaque monkeys, spermatozoa require both washing and treatment with caffeine and cyclic AMP to support acquisition of fertilizing ability in vitro (Boatman and Bavister, 1984). Golden hamster epididymal spermatozoa under in vitro conditions also require treatment with chemical mediators, both to sustain motility (hypotaurine) and to stimulate acrosome reactions (catecholamines such as adrenaline; Leibfried and Bavister, 1982; Bavister, 1989; Boatman et al., 1990). Although hamster, mouse, dog and human spermatozoa thrive on or require glucose in the culture medium (Bavister and Yanagimachi, 1977; Mahi and Yanagimachi, 1978; Fraser and Herod, 1990; Rogers and Perreault, 1990; Travis et al., 2001), glucose inhibits or greatly delays the completion of capacitation in guinea-pig and bull spermatozoa (Rogers and Yanagimachi, 1975; Parrish et al., 1989a; Vredenburgh-Wilberg and Parrish, 1995). In bull spermatozoa, this inhibition is the result of glycolysis blocking the normal increase in intracellular $\mathrm{pH}$ that accompanies capacitation with heparin (Parrish et al., 1989a). An increase in intracellular $\mathrm{pH}$ also appears to accompany the acrosome reaction of mouse spermatozoa (Rockwell and Storey, 2000). Even if they are artifacts of the in vitro culture of spermatozoa, these apparently contradictory capacitation requirements need to be resolved if a common mechanism is to be established and the events involved elucidated.

One consistent feature of early culture systems for supporting in vitro sperm capacitation and acrosome reactions was the use of biological fluids (usually follicular or cumulus oophorus fluids; Iwamatsu and Chang, 1969; Yanagimachi, 1969a,b; Bavister, 1982). These fluids were later replaced by serum albumin (Bavister, 1969, 1981, 1982, 1989; Miyamoto and Chang, 1973a,b,c; Hoppe and Whitten, 1974; Davis, 1976). In modern IVF protocols, either bovine or human serum albumin is almost always used, although cumulus oophorus fluids may also be present. The way in which serum albumin supports capacitation and acrosome reactions is still not fully understood. At least two mechanisms have been proposed: removal of either lipids or zinc ions from sperm membranes by albumin, leaving them more unstable and thus able to undergo membrane fusion leading to acrosome reactions. Some of the earliest work on this topic was done by Davis et al. $(1979,1980)$ who showed that in a capacitating culture medium, serum albumin depleted cholesterol from rat spermatozoa while transferring phosphatidylcholine to them. Further evidence for involvement of cholesterol depletion in sperm capacitation was provided by Langlais 
and Roberts (1985) and Langlais et al. (1988). Alternatively or additionally, serum albumin depletes zinc from spermatozoa by chelation (zinc stabilizes membranes and is a counter-ion to calcium, inhibiting many of its functions). Hamster spermatozoa can be capacitated in vitro without albumin, using a chemical chelator that depletes zinc concentrations in spermatozoa by $40 \%$ or more (Andrews et al., 1994), but these spermatozoa could not undergo acrosome reactions without addition of serum albumin, even in the presence of zonae pellucidae (Andrews and Bavister, 1989). When albumin was separated from spermatozoa by a semi-permeable membrane, acrosome reactions did not occur (Dow and Bavister, 1989). In spite of much attention, the way in which albumin supports acquisition of sperm fertilizing ability is unknown, in part because of the problem of discriminating which spermatozoa in a suspension are actually capacitated, but also because of fluctuating concentrations of contaminants in commercial serum albumin preparations, such as fatty acids (Chen, 1967) and even a factor that activates the phosphatidylinositol system in a number of cells (Tigyi et al., 1991), which may counteract the biological activities of serum albumin preparations, or which conversely may even be responsible for them. Certainly, the biological activity of these preparations is batch variable, but not particularly species-specific. Alternative methods for capacitating spermatozoa would be particularly useful as there is potential for disease transmission by using bovine or human serum albumin preparations. The induction of acrosome reactions by lysophosphatidylcholine showed that sulphated glycoconjugates, including heparin, could capacitate bovine spermatozoa (Parrish et al., 1989b). Further research into non-serum-derived capacitating compounds is needed in view of the potential for transmitting bovine spongiform encephalopathy or Creutzfeldt-Jakob disease from infected animal or human donors, as well as for elucidating the mechanism of capacitation.

\section{Assessment of sperm fertilizing ability}

\section{Egg penetration or fertilization as tests for capacitation} and the acrosome reaction

In early studies, in the absence of more suitable methods, most information relating to capacitation was derived from experiments involving penetration or fertilization of eggs. Rabbits were the most widely used animal in such experiments, not only because the need for capacitation had been clearly established in this species, but the relatively short and predictable fertilizable life of rabbit eggs was particularly useful in the capacitation test system (as described by Soupart, 1967). The major disadvantage of this method was that the onset and duration of ovulation in rabbits are highly variable (Walton and Hammond, 1928; Harper, 1961, 1963). Although this objection was largely overcome by the technical refinement of adding recently ovulated eggs to the preincubated spermatozoa instead of vice versa (Harper, 1970), the method as a whole lacks precision. It is not easy to examine the biochemical conditions prevailing in the female reproductive tract during capacitation of spermatozoa, and it is not possible to control these conditions, except crudely by making drastic hormonal or surgical changes to investigate the effect upon capacitation (for example, see Soupart and Orgebin-Crist, 1966; Bedford, 1970b). In addition, once capacitated spermatozoa are incubated with eggs in the female reproductive tract, little further information can be gained concerning the acrosome reaction and other events associated with egg penetration.

It was realized that more precise and perhaps less conflicting information could be gained by capacitating rabbit spermatozoa in vitro, but the validity of early claims to have achieved this (Kirton and Hafs, 1965; Ericsson, 1969; Johnson and Hunter, 1971) is in some doubt because of the lack of confidence in the rabbit capacitation test system (see above). This situation would be improved by fertilizing rabbit eggs consistently in vitro. However, the necessary degree of reproducibility was initially difficult to achieve (for example, see Fraser et al., 1971) and reproducible protocols were devised only after methods were developed for capacitating spermatozoa in vitro (Brackett and Oliphant, 1975; Hosoi et al., 1982), by which time, IVF in rodents had become the predominant approach for assessment of sperm capacitation and the acrosome reaction.

\section{In vitro fertilization in the hamster}

Golden hamsters are highly suitable for the study of sperm capacitation, and a well-defined protocol for achieving IVF in this species has been described by Bavister (1989). There were numerous advantages when hamsters were used for IVF studies: not only were capacitation of spermatozoa and penetration of eggs accomplished easily in vitro, but the hamster acrosome reaction (like that in rabbits, guinea-pigs and dogs) is pronounced enough to be discernable under the phase-contrast microscope in living, motile spermatozoa (Yanagimachi and Chang, 1964; Yanagimachi, 1966, 1972, 1994; Mahi and Yanagimachi, 1978), so that the percentage of reacted spermatozoa can be readily assessed at any time.

However, a problem encountered with the early attempts to fertilize hamster eggs in vitro was the highly variable outcome of the experiments, ranging from near 0 to $80-90 \%$ fertilization of eggs. This variability was the result of differences in the $\mathrm{pH}$ of the culture medium used for IVF, which was uncontrolled and altered by the numbers of live spermatozoa present. After $\mathrm{pH}$ was controlled using a bicarbonate- $\mathrm{CO}_{2}$ buffer system, high, reproducible frequencies of IVF were obtained (Bavister, 1969). These early experiments with hamster spermatozoa were the first to show that occurrence of the acrosome reaction, sperm binding to the zona pellucida and fertilization are $\mathrm{pH}$ dependent events. This culture system was then used successfully for the first documented human IVF (Bavister 
et al., 1969; Edwards et al., 1969). The sequence of experiments that connected hamster IVF to the first human IVF is described by Bavister (2002). Studies by Miyamoto and Chang (1974) showed that $\mathrm{pH}$ was also important for IVF in mice and rats.

In virtually all IVF experiments with hamster gametes, spermatozoa have been obtained from the cauda epididymidis. Not only is it easy to obtain viable spermatozoa in this way, but the time-course of capacitation and penetration of eggs in vitro with epididymal spermatozoa (Barros, 1968; Yanagimachi, 1969b) is similar to that observed in vivo after normal mating (Strauss, 1956; Chang and Sheaffer, 1957; Yanagimachi, 1966). Moreover, methods for routinely collecting ejaculated hamster spermatozoa have not been developed. Although it is more practical to investigate capacitation using hamster epididymal spermatozoa and the IVF approach, it must be kept in mind that capacitation of epididymal spermatozoa may not be identical to capacitation of ejaculated spermatozoa, that events occurring in culture conditions may not be the same as events after normal mating, and that the process of capacitation in hamster spermatozoa may not be fully representative of capacitation in other mammals. One obvious difference between conditions in vitro and in vivo is that under most IVF conditions, a very large population of spermatozoa is present but only a small proportion seems capable of penetrating zonae pellucidae in a timely manner, whereas in vivo, a small number of spermatozoa is present at the site and time of fertilization but most of the spermatozoa appear to be capable of fertilizing oocytes (Austin, 1951; Zamboni, 1970; Yanagimachi and Mahi, 1976). The total number of spermatozoa in a typical IVF culture drop often exceeds the number of eggs present by three or more orders of magnitude. However, when the culture conditions for hamster sperm survival and capacitation in vitro were optimized, very small numbers of spermatozoa $(\leqslant 5)$ could be used for gamete co-incubation and were capable of fertilizing eggs (Bavister, 1979).

\section{Alternative sperm fertility assays}

The ability of spermatozoa to penetrate the zona pellucida and to fertilize eggs is the only unequivocal test for completion of capacitation and the ensuing physiological acrosome reaction. However, IVF is far from satisfactory as a means to evaluate sperm fertilizing ability in a large sperm population, as it introduces large experimental variations, such as differences in the fertilizability of eggs, and yields no information on the frequency of capacitation. One obvious reason for this problem is the rapid operation of the block to polyspermy (Austin and Braden, 1954; StewartSavage and Bavister, 1988), such that only one spermatozoon, or at most several, can gain access to the oocyte before the properties of the zona pellucida are altered, preventing further sperm entry. One way to overcome this limitation to testing sperm fertilizing ability is to inhibit the block to polyspermy, for example, by storing oocytes for a time in concentrated salt solutions (Yanagimachi et al., 1979; Boatman et al., 1988; Yoshimatsu et al., 1988). When the block to polyspermy is destroyed in this way, many, perhaps hundreds of, spermatozoa can penetrate each zona pellucida, thus increasing the efficiency of this 'capacitation detection' system by two or more orders of magnitude (Boatman et al., 1988). This method has also been used to assess the fertility of spermatozoa from endangered species using oocytes from related common animals (Andrews et al., 1992). A different approach is to count the proportion of spermatozoa able to respond to a challenge that induces acrosome loss, such as lysophosphatidylcholine (Parrish et al., 1988, 1989b), after capacitation treatments, although how accurately this procedure mimics the natural acrosome reaction is not clear.

An early attempt to devise a chemical test for capacitation was reported by Ericsson $(1967 a, b)$. This test involved the fluorescent labelling of spermatozoa with tetracycline hydrochloride and the subsequent removal of fluorescence during capacitation. Unfortunately, the time courses, sites and conditions of fluorescence removal and of capacitation were not strictly correlated (Vaidya et al., 1969), so the test was of dubious value for the study of capacitation. Nevertheless, this approach was a valuable stimulus to further attempts to develop chemical tests for capacitation. A refinement of this approach uses chlortetracycline (CTC) fluorescence to quantitate mouse sperm capacitation (Saling and Storey, 1979); distinct patterns of fluorescence change as capacitation progresses (Ward and Storey, 1984). This assay has also been used with human spermatozoa (Lee et al., 1987).

Johnson and Hunter (1970) used a fluorescent antibody technique to identify rabbit sperm-specific and spermcoating antigens; the sperm-coating antigens were removed after prolonged incubation in rabbit uteri, re-exposing acrosomal sperm-specific sites. This approach seemed promising, not only as a potential test for capacitation, but also as a method of investigating the nature of this process. Brackett and Oliphant (1975) measured the removal of rabbit sperm surface antigens as a progressive indicator of capacitation taking place in vitro.

The occurrence of the sperm acrosome reaction, in the absence of fertilization, has often been used to indicate that capacitation has taken place (Barros and Garavagno, 1970). However, structural changes in the acrosome are not necessarily the result of capacitation of spermatozoa, but can also occur under other circumstances, as degenerative changes (Blom, 1945; Hancock, 1952; Austin and Bishop, 1958c) or 'false' acrosome reactions that are not dependent on previous capacitation (Bedford, 1969b). Thus, the occurrence of an acrosome reaction is an insufficient indication that capacitation has occurred, except in species in which the acrosomes are very large (for example, golden hamsters and guinea-pigs), so that the acrosome reaction (detachment or loss) can be seen clearly in freely motile spermatozoa that do not appear to be moribund (Yanagimachi, 1994). 
Two remarkable procedures derived from IVF have been devised for evaluating sperm fertilizing ability: one procedure uses oocytes without zonae pellucidae, and the other uses zonae pellucidae without oocytes. The hamster egg can be fertilized by spermatozoa of other species if the zona pellucida is removed (Yanagimachi, 1994). This 'zona-free penetration assay' is very useful for evaluating human sperm chromosomes (Rudak et al., 1978; Martin, 1985) and has been used as a surrogate test for human sperm fertility (Yanagimachi et al., 1976; Rogers et al., 1979); however, its predictive value is dubious, and most clinical IVF programmes no longer use it. A major problem with this assay is that, in the absence of the zona pellucida, which is a natural stimulator of acrosome reactions, spermatozoa may fail to exhibit acrosome reactions or to fertilize hamster eggs, yet remain capable of effecting fertilization of homologous zona-intact (human) eggs (giving a false negative result). Conversely, spermatozoa from an infertile male may be artificially induced to undergo acrosome reactions by the conditions of the test, such as overnight incubation of the sperm sample at $4^{\circ} \mathrm{C}$, and thus become able to fuse with hamster egg plasma membranes and form pronuclei (giving a false positive result). The 'hemi-zona assay' avoids the problems with the hamster egg zona-free penetration assay by using human zonae pellucidae to gauge sperm-binding capability, which should correlate with fertilizing ability. Each zona pellucida is bisected and one half is inseminated with a sperm sample of unknown fertility. The resulting sperm binding frequency is compared directly with sperm binding to the matched half-zona pellucida using a control sample of known fertility (Oehninger et al., 1992; Franken et al., 1993; Coddington et al., 1994). This assay does not measure ability of the spermatozoa to form pronuclei because no egg is present.

A variant of IVF that has gained great popularity in recent years is ICSI, in which a single spermatozoon is selected and injected into the egg cytoplasm with a fine pipette. The first successful human ICSI was reported by Palermo et al. (1992) but this approach was first demonstrated with animal gametes many years earlier (Uehara and Yanagimachi, 1977). Uehara and Yanagimachi (1977) showed that hamster spermatozoa from the cauda epididymidis could undergo decondensation and form pronuclei after injection into eggs. This demonstration that testicular spermatozoa could form pronuclei after ICSI pre-dated by many years the use of this technique for azoospermic men (Palermo et al., 1999). ICSI in humans is very effective for addressing 'male factor' infertility (van Steirteghem et al., 1993; Oehninger et al., 1995) but some clinics routinely use ICSI in place of IVF for convenience. Although numerous offspring have been born after ICSI in humans (Palermo et al., 1992, 1999; van Steirteghem et al., 1993; Oehninger et al., 1995; Bonduelle et al., 1999, 2002) and in animals, there are concerns about potential abnormalities during fertilization and even in the offspring themselves as a result of this technique (Kent-First et al., 1996; Wakayama et al., 1998; Hewitson et al., 2000;
Terada et al., 2000) indicating a need for more animal testing with ICSI to provide a more complete understanding of the long-term consequences (Yanagimachi, 1995). Although one major study showed no differences in defects at birth (Bonduelle et al., 2002), it is possible that problems resulting from ICSI will be revealed later in life.

\section{Conclusions (2002)}

During the last 30 years, it has become clear that IVF can be achieved in many mammals and has important practical applications in human clinical medicine and in animal breeding. It is apparent from evaluating both the early and the contemporary literature that successful fertilization of mammalian eggs in vitro has depended upon the use of spermatozoa that have undergone capacitation, either in vivo or in vitro. However, precise information concerning the nature of capacitation has been gained by studying the requirements for accomplishing IVF. Therefore, the studies of IVF and of capacitation are complementary, so it is not surprising that knowledge about these processes has advanced in parallel.

The preceding account of early IVF studies illustrates the rather primitive state of knowledge during the first 20 years after the discovery of capacitation about the mechanisms of this process and of the ensuing acrosome reaction, and about the functional significance of these events for fertilization in mammals. In the ensuing 30 years, much has been learned on these topics, and IVF technology is currently being applied routinely in a wide variety of species. However, several key questions remain completely or partially unanswered. For example, what is the stimulus for the initiation of capacitation within the female reproductive tract? What molecular events are involved in capacitation? How exactly does the completion of capacitation lead to the acrosome reaction? How does serum albumin induce capacitation and the acrosome reaction? Considering that it takes only one or a few spermatozoa to fertilize oocytes within the oviduct, why are so many spermatozoa needed to effect fertilization in vitro? How is capacitation stimulated within the female reproductive tract in species such as the hamster or rhesus monkey that require chemical stimulators for supporting sperm capacitation in vitro? Does the application of ICSI make IVF obsolete or redundant, or does IVF, by preserving the natural mechanisms for selecting against the entry of abnormal spermatozoa into the oocyte, safeguard against defects that may be introduced using ICSI? Full answers to these perplexing questions concerning fertilization should be provided during the next 30 years of research into this fundamental aspect of mammalian reproduction.

I am grateful to the Marshall Laboratory, University of Cambridge, for supporting my graduate studies from 1967 to 1972. I thank Bob Edwards, David Whittingham and John Marston for their advice and guidance. Above all, I am deeply indebted to my PhD supervisor, C. R. 'Bunny' Austin, to whom this article is most affectionately dedicated. 


\section{References}

Key references are identified by asterisks.

Abeydeera LR (2002) In vitro production of embryos in swine Theriogenology $57256-273$

Adams CE and Chang MC (1962a) The effect of delayed mating on fertilisation in the rabbit Journal of Experimental Zoology 151 155-158

Adams CE and Chang MC (1962b) Capacitation of rabbit spermatozoa in the Fallopian tube and in the uterus Journal of Experimental Zoology 151 159-165

Andrews JC and Bavister BD (1989) Hamster zonae pellucidae cannot induce physiological acrosome reactions in chemically capacitated hamster spermatozoa in the absence of albumin Biology of Reproduction $40117-122$

Andrews JC, Howard JG, Bavister BD and Wildt DE (1992) Sperm capacitation in the domestic cat (Felis catus) and leopard cat (Felis bengalensis) as studied with a salt-stored zona pellucida penetration assay Molecular Reproduction and Development 31 200-207

Andrews JC, Nolan JP, Hammerstedt RH and Bavister BD (1994) Role of zinc during hamster sperm capacitation Biology of Reproduction $\mathbf{5 1}$ 1238-1247

Asch RH, Balmaceda JP, Ellsworth LR and Wong PC (1986) Preliminary experiences with gamete intrafallopian transfer (GIFT) Fertility and Sterility 45 366-371

*Austin CR (1951) Observations on the penetration of the sperm into the mammalian egg Australian Journal of Scientific Research Series B 4 581-589

Austin CR (1952) The 'capacitation' of the mammalian sperm Nature (London) 170326

Austin CR (1956a) Activation of eggs by hypothermia in rats and hamsters Journal of Experimental Biology 33 338-347

Austin CR (1956b) Effects of hypothermia and hyperthermia on fertilisation in rat eggs Journal of Experimental Biology 33 348-357

Austin CR (1961) Fertilisation of mammalian eggs in vitro. International Review of Cytology 12 337-359

Austin CR (1963) Acrosome loss from the rabbit spermatozoa in relation to entry into the egg Journal of Reproduction and Fertility 6 313-314

Austin CR (1967) Capacitation of spermatozoa International Journal of Fertility 12 25-31

Austin CR (1969) Sperm capacitation - biological significance in various species. In Mechanisms Involved in Conception: Advances in the Biosciences 4 pp 5-10 Ed. G Raspe. Pergamon Press, Oxford

Austin CR and Bishop MWH (1958a) Role of the rodent acrosome and perforatorium in fertilisation Proceedings of the Royal Society, Series $B$ 149 241-248

Austin CR and Bishop MWH (1958b) Capacitation of mammalian spermatozoa Nature (London) 181851

Austin CR and Bishop MWH (1958c) Some features of the acrosome and perforatorium in mammalian spermatozoa Proceedings of the Royal Society, Series B 149 234-240

Austin CR and Braden AWH (1954) Time relations and their significance in the ovulation and penetration of eggs in rats and rabbits Australian Journal of Biological Science 7 179-194

Austin CR and Braden AWH (1956) Early reaction of the rodent egg to spermatozoa penetration Journal of Experimental Biology 33 358-365

Barnett DK and Bavister BD (1992) Hypotaurine requirement for in vitro development of golden hamster one-cell embryos into morulae and blastocysts, and production of term offspring from in vitro fertilized ova Biology of Reproduction 47 297-304

Barros C (1968) In vitro capacitation of golden hamster spermatozoa Anatomical Record 160310 (Abstract)

Barros C and Austin CR (1967) In vitro fertilisation and the sperm acrosome reaction in the hamster Journal of Experimental Zoology 166 317-323

Barros C and Garavagno A (1970) Capacitation of hamster spermatozoa with blood sera Journal of Reproduction and Fertility 22 381-384

Barros C, Bedford JM, Franklin LE and Austin CR (1967) Membrane vesiculation as a feature of the mammalian acrosome reaction Journal of Cell Biology $34 \mathrm{C} 1-\mathrm{C} 5$
Bavister BD (1969) Environmental factors important for in vitro fertilisation in the hamster Journal of Reproduction and Fertility 18 544-545

Bavister BD (1971) A Study of In Vitro Fertilisation and Capacitation in the Hamster PhD Dissertation, University of Cambridge

Bavister BD (1979) Fertilization of hamster eggs in vitro at sperm egg ratios close to unity Journal of Experimental Zoology 210 259-264

Bavister BD (1981) Substitution of a synthetic polymer for protein in a mammalian gamete culture system Journal of Experimental Zoology 217 $45-51$

Bavister BD (1982) Evidence for a role of post-ovulatory cumulus components in supporting fertilizing ability of hamster spermatozoa Journal of Andrology 3 365-372

Bavister BD (1986) Animal in vitro fertilization and embryo development. In Manipulation of Mammalian Development pp 81-148 Ed. RBL Gwatkin. Plenum Press, New York

Bavister BD (1989) A consistently successful procedure for in vitro fertilization of golden hamster eggs Gamete Research 23 139-158

Bavister BD (1995) Culture of preimplantation embryos: facts and artifacts Human Reproduction Update 191-148

Bavister BD (2002) How animal research led to the first documented human IVF Reproductive Biomedicine Online 4 Supplement 1 24-29

Bavister BD and Yanagimachi R (1977) The effects of sperm extracts and energy sources on the motility and acrosome reaction of hamster spermatozoa in vitro. Biology of Reproduction 16 228-237

Bavister BD, Edwards RG and Steptoe PC (1969) Identification of the midpiece and tail of the spermatozoon during fertilisation of human eggs in vitro. Journal of Reproduction and Fertility 20 159-160

Bavister BD, Boatman DE, Leibfried ML, Loose M and Vernon MW (1983) Fertilization and cleavage of rhesus monkey oocytes in vitro. Biology of Reproduction 28 983-999

Bedford JM (1963) Morphological reaction of spermatozoa in the female reproductive tract of the rabbit Journal of Reproduction and Fertility 6 245-255

Bedford JM (1964) Fine structure of the sperm head in ejaculate and uterine spermatozoa of the rabbit Journal of Reproduction and Fertility 7 221-228

Bedford JM (1965) Effect of environment on phagocytosis of rabbit spermatozoa Journal of Reproduction and Fertility 9 249-256

Bedford JM (1967) Experimental requirement for capacitation and observations on ultrastructural changes in rabbit spermatozoa during fertilisation Journal of Reproduction and Fertility Supplement 2 35-48

Bedford JM (1968) Ultrastructural changes in the sperm head during fertilisation in the rabbit American Journal of Anatomy 123 329-357

Bedford JM (1969a) Limitations of the uterus in the development of the fertilising ability (capacitation) of spermatozoa Journal of Reproduction and Fertility Supplement 8 19-26

Bedford JM (1969b) Morphological aspects of sperm capacitation in mammals. In Mechanisms Involved in Conception: Advances in the Biosciences 4 pp 35-50 Ed. G Raspe. Pergamon Press, Oxford

Bedford JM (1970a) Sperm capacitation and fertilisation in mammals Biology of Reproduction Supplement 2 128-158

Bedford JM (1970b) Influence of oestrogen and progesterone on sperm capacitation in the reproductive tract of the female rabbit Journal of Endocrinology 46 191-200

Bedford JM (1970c) Observations on the properties of a potent sperm head agglutinin in the semen of a fertile rabbit Journal of Reproduction and Fertility 22 193-196

Bernstein MH (1966) Modification of sperm structure in capacitation Journal of Cell Biology 31 12A (Abstract)

Blom E (1945) Spontaneous detachment of the galea capitis in spermia of bull and stallion Scandinavisk Veterinaertiddskrift 35 779-783

Blom E (1963) The galea capitis and apical body in bull sperm and the fertilisation process International Journal of Fertility 8 447-452

Boatman DE and Bavister BD (1984) Stimulation of rhesus monkey sperm capacitation by cyclic nucleotide mediators Journal of Reproduction and Fertility 77 357-366

Boatman DE, Andrews JC and Bavister BD (1988) A quantitative assay for capacitation: evaluation of multiple sperm penetration through the zona pellucida of salt-stored hamster eggs Gamete Research 19 19-29 
Boatman DE, Bavister BD and Cruz E (1990) Addition of hypotaurine can reactivate immotile golden hamster spermatozoa Journal of Andrology $1166-72$

Bondioli KR and Wright RW, Jr (1980) Influence of culture media on in vitro fertilization of ovine tubal oocytes Journal of Animal Science $\mathbf{5 1}$ 660-667

Bonduelle M, Camus M, De Vos A et al. (1999) Seven years of intracytoplasmic sperm injection and follow-up of 1987 subsequent children Human Reproduction 14 Supplement $1243-264$

Bonduelle M, Liebaers I, Deketelaere V, Derde MP, Camus M, Devroey P and van Steirteghem A (2002) Neonatal data on a cohort of 2889 infants born after ICSI (1991-1999) and of 2995 infants born after IVF (1983-1999) Human Reproduction 17 671-694

Bowen RA (1977) Fertilization in vitro of feline ova by spermatozoa from the ductus deferens Biology of Reproduction 17 144-147

Brackett BG (1969) Effects of washing the gametes on fertilisation in vitro Fertility and Sterility $20127-142$

Brackett BG and Oliphant G (1975) Capacitation of rabbit spermatozoa in vitro. Biology of Reproduction 12 260-274

Brackett BG, Hall JL and Oh YK (1978) In vitro fertilizing ability of testicular, epididymal, and ejaculated rabbit spermatozoa Fertility and Sterility 29 571-582

Brackett BG, Oh YK, Evans JF and Donawick WJ (1978) In vitro fertilization of cow ova Theriogenology 989 (Abstract)

Braden AWH and Austin CR (1954) Fertilisation of the mouse eggs and the effect of delayed coitus and of hot-shock treatment Australian Journal of Biological Science $7552-565$

*Chang MC (1951) Fertilising capacity of spermatozoa deposited into the Fallopian tubes Nature (London) 168697

Chang MC (1952) Fertilisability of rabbit ova and the effects of temperature in vitro on their subsequent fertilisation and activation in vivo. Journal of Experimental Zoology 121 351-381

Chang MC (1954) Development of parthenogenetic rabbit blastocysts induced by low temperature storage of unfertilised ova Journal of Experimental Zoology 125 127-150

Chang MC (1955) Development of fertilising capacity of rabbit spermatozoa in the uterus Nature (London) 175 1036-1037

*Chang MC (1959) Fertilisation of rabbit ova in vitro. Nature (London) 179 466-467

Chang MC (1968) In vitro fertilisation of mammalian eggs Journal of Animal Science 27 Supplement $\mathbf{1} 15-22$

Chang MC (1969) Hormonal regulation of sperm capacitation. In Mechanisms Involved in Conception: Advances in the Biosciences 4 pp 13-24 Ed. G Raspe. Pergamon Press, Oxford

Chang MC and Sheaffer D (1957) Number of spermatozoa ejaculated at copulation transported into the female tract and present in the male tract of the golden hamster Journal of Heredity 48 107-109

Chang MC and Yanagimachi R (1963) Fertilisation of ferret ova by deposition of epididymal sperm into the ovarian capsule with special reference to the fertilisable life of ova and the capacitation of sperm Journal of Experimental Zoology 154 175-188

Chang MC, Hunt DM and Marston JH (1971) The capacitation time and fertilising life of snowshoe hare spermatozoa in the female tract of rabbit Journal of Reproduction and Fertility 25 287-289

Chen RF (1967) Removal of fatty acids from serum albumin by charcoal treatment Journal of Biological Chemistry 242 173-181

Coddington CC, Oehninger SC, Olive DL, Franken DR, Kruger TF and Hodgen GD (1994) Hemizona index (HZI) demonstrates excellent predictability when evaluating sperm fertilizing capacity in in vitro fertilization patients Journal of Andrology 15 250-254

Colwin AL and Colwin LH (1965) Suggested similarity between early events of fertilisation in certain mammals and vertebrates Anatomical Record 151447

Colwin LH and Colwin AL (1967) Membrane fusion in relation to sperm-egg association. In Fertilisation Vol. I pp 295-367 Eds CB Metz and A Monroy. Academic Press, New York

Cross PC and Brinster RL (1970) In vitro development of mouse oocytes Biology of Reproduction 3 298-307

Crozet N, Huneau D, Desmedt V, Theron MC, Szollosi D, Torres S and
Sevellec C (1987) In vitro fertilization with normal development in the sheep Gamete Research 16 159-170

Dan JC (1956) The acrosome reaction International Review of Cytology 5 365-393

Dan JC (1967) Acrosome reaction and lysins. In Fertilisation Vol. I pp 237-293 Eds CB Metz and A Monroy. Academic Press, New York

Dauzier L and Thibault C (1956) Recherche experimentale sur la maturation des gametes males chez les mammifieres par l'etude de la fecondation in vitro de l'oeuf de lapine Proceedings of the 3rd International Congress on Animal Reproduction (Cambridge) pp 58-61

Dauzier L and Thibault C (1959) Donnees nouvelles sur la fecondation in vitro de la lapine et de la brebis Comptes Rendus de l'Academie de Science (Paris) $\mathbf{2 4 8}$ 2655-2656

Dauzier L, Thibault C and Wintenberger S (1954) La fecondation in vitro de I'oeuf de lapine Comptes Rendus de l'Academie de Science (Paris) 238 844-845

Davis BK (1976) Influence of serum albumin on the fertilizing ability in vitro of rat spermatozoa Proceedings of the Society for Experimental Biology and Medicine 151 240-243

Davis BK, Byrne R and Hungund B (1979) Studies on the mechanism of capacitation. II. Evidence for lipid transfer between plasma membrane of rat sperm and serum albumin during capacitation in vitro. Biochimica et Biophysica Acta 558 257-266

Davis BK, Byrne R and Bedigian K (1980) Studies on the mechanism of capacitation: albumin-mediated changes in plasma membrane lipids during in vitro incubation of rat sperm cells Proceedings National Academy of Sciences USA 77 1546-1550

Demott RP and Suarez SS (1992) Hyperactivated sperm progress in the mouse oviduct Biology of Reproduction 46 779-785

Dickmann Z and Dziuk PJ (1964) Sperm penetration of the zona pellucida of the pig egg Journal of Experimental Biology 41 603-608

Dow MPD and Bavister BD (1989) Direct contact is required between serum albumin and hamster spermatozoa for capacitation in vitro. Gamete Research 23 171-180

Edwards RG (1965) Maturation in vitro of human ovarian oocytes Lancet ii 926-929

Edwards RG, Bavister BD and Steptoe PC (1969) Early stages of fertilisation in vitro of human oocytes matured in vitro. Nature (London) 221 632-635

Edwards RG, Steptoe PC and Purdy JM (1970) Fertilisation and cleavage in vitro of preovulatory human oocytes Nature (London) 227 1307-1309

Ericsson RJ (1967a) Technology, physiology and morphology of sperm capacitation Journal of Reproduction and Fertility Supplement 2 65-74

Ericsson RJ (1967b) Fluorimetric method for the measurement of sperm capacitation Proceedings of the Society for Experimental Biology and Medicine 125 1115-1118

Ericsson RJ (1969) Capacitation in vitro of rabbit sperm with mule eosinophils Nature (London) 221 568-569

First NL, Short RE, Peters JB and Stratman FW (1968) Transport of boar spermatozoa in estrual and luteal sows Journal of Animal Science $\mathbf{2 7}$ 1032-1036

Fissore RA, Gordo AC and Wu H (1998) Activation of development in mammals: is there a role for a sperm cytosolic factor? Theriogenology $\mathbf{4 9}$ 43-52

Franken DR, Acosta AA, Kruger TF, Lombard CJ, Oehninger S and Hodgen GD (1993) The hemizona assay: its role in identifying male factor infertility in assisted reproduction Fertility and Sterility 59 1075-1080

Franklin LE, Barros C and Fussell EN (1970) The acrosomal region and the acrosome reaction in sperm of the golden hamster Biology of Reproduction 3 180-200

Fraser LR and Herod JE (1990) Expression of capacitation-dependent changes in chlortetracycline fluorescence patterns in mouse spermatozoa requires a suitable glycolysable substrate Journal of Reproduction and Fertility 88 611-621

Fraser LR, Dandekar PV and Vaidya RA (1971) In vitro fertilisation of tubal rabbit ova partially or totally denuded of follicular cells Biology of Reproduction 4 229-233

Gould KG (1983) Ovum recovery and in vitro fertilization in the chimpanzee Fertility and Sterility 40 378-383 
Gould KG, Cline EM and Williams WL (1973) Observations on the induction of ovulation and fertilization in vitro in the squirrel monkey (Saimiri sciureus). Fertility and Sterility 24 260-268

Hamner CE, Jennings LL and Sojka NJ (1970) Cat (Felis catus L) spermatozoa require capacitation Journal of Reproduction and Fertility 23 477-480

Hancock JL (1952) The morphology of bull spermatozoa Journal of Experimental Biology 29 445-453

Harper MJK (1961) The time of ovulation in the rabbit following the injection of luteinizing hormone Journal of Endocrinology 22 147-152

Harper MJK (1963) Ovulation in the rabbit. The time of follicular rupture and expulsion of the eggs in relation to injection of luteinizing hormone Journal of Endocrinology 26 307-316

Harper MJK (1970) Factors influencing sperm penetration of rabbit eggs in vivo. Journal of Experimental Zoology 173 47-62

Hasler JF (1998) The current status of oocyte recovery, in vitro embryo production, and embryo transfer in domestic animals, with an emphasis on the bovine Journal of Animal Science 76 52-74

Hewitson L, Simerly C, Dominko T and Schatten G (2000) Cellular and molecular events after in vitro fertilization and intracytoplasmic sperm injection Theriogenology 53 95-104

Hoppe PC and Whitten WK (1974) An albumin requirement for fertilization of mouse eggs in vitro. Journal of Reproduction and Fertility 39 433-436

Hosoi Y, Niwa K, Hatanaka S and Iritani A (1981) Fertilization in vitro of rabbit eggs by epididymal spermatozoa capacitated in a chemically defined medium Biology of Reproduction 24 637-642

Hunter RHF (1969) Capacitation in the golden hamster with special reference to the influence of the uterine environment Journal of Reproduction and Fertility 20 223-237

Hunter RHF and Dziuk PJ (1968) Sperm penetration of pig eggs in relation to the timing of ovulation and insemination Journal of Reproduction and Fertility 15 199-208

Iritani A, Gomes WR and VanDemark NL (1969) The effect of whole, dialysed and heated female genital tract fluids on respiration of rabbit and ram spermatozoa Biology of Reproduction 1 77-82

Iwamatsu T and Chang MC (1969) In vitro fertilization of mouse eggs in the presence of bovine follicular fluid Nature 224 919-920

Iwamatsu T and Chang MC (1970) Further investigation of capacitation of sperm and fertilisation of mouse eggs in vitro. Journal of Experimental Zoology 175 271-281

Johnson WL and Hunter AG (1970) Immunofluorescent changes associated with maturation of rabbit sperm Biology of Reproduction, Society for the Study of Reproduction 3rd annual meeting, Ohio Abstract 15

Johnson WL and Hunter AG (1971) Partial in vitro capacitation with $\beta$ amylase and $\beta$-glucuronidase of rabbit sperm and association of sperm and semen antigens Journal of Dairy Science 54786 (Abstract)

Katz D and Yanagimachi R (1980) Movement characteristics of hamster spermatozoa within the oviduct Biology of Reproduction 22 759-764

Katz DF, Drobnis EZ and Overstreet JW (1989) Factors regulating mammalian sperm migration through the female reproductive tract and oocyte vestments Gamete Research 22 443-469

Kent-First MG, Kol S, Muallem A, Ofir R, Manor D, Blazer S, First N and Itskovitz-Eldor J (1996) The incidence and possible relevance of $Y$-linked microdeletions in babies born after intracytoplasmic sperm injection and their infertile fathers Molecular Human Reproduction 2 943-950

Khosla S, Dean W, Reik W and Feil R (2001) Culture of preimplantation embryos and its long-term effects on gene expression and phenotype Human Reproduction Update 7 419-427

Kirton KT and Hafs HD (1965) Sperm capacitation by uterine fluids or $\beta$ amylase in vitro. Science (New York) 150 618-619

Kuehl TJ and Dukelow WR (1975) Fertilization in vitro of Saimiri sciureus follicular oocytes Journal of Medical Primatology 4 209-216

Langlais J and Roberts KD (1985) A molecular membrane model of sperm capacitation and the acrosome reaction of mammalian spermatozoa Gamete Research 12 183-224

Langlais J, Kan FW, Granger L, Raymond L, Bleau G and Roberts KD (1988) Identification of sterol acceptors that stimulate cholesterol efflux from human spermatozoa during in vitro capacitation Gamete Research 20 185-201
Lauderdale JW and Ericsson RJ (1970) Physiological conditions affecting the ability of cattle uteri to influence the fertilising capacity of sperm Biology of Reproduction 2 179-184

Lee MA, Trucco GS, Bechtol KB, Wummer N, Kopf GS, Blasco L and Storey BT (1987) Capacitation and acrosome reactions in human spermatozoa monitored by a chlortetracycline fluorescence assay Fertility and Sterility $\mathbf{4 8}$ 649-658

Leibfried ML and Bavister BD (1982) Effects of epinephrine and hypotaurine on in vitro fertilization in the golden hamster Journal of Reproduction and Fertility 66 87-93

Long JA (1912) The living eggs of rats and mice with a description of apparatus for obtaining and observing them Publications in Zoology of the University of California (Berkeley) 9 105-136

Mahajan SC and Menge AC (1966) Influence of uterine environment on the fertilising capacity of sperm in cattle Journal of Animal Science 25 1083-1086

Mahi CA and Yanagimachi R (1976) Maturation and sperm penetration of canine ovarian oocytes in vitro. Journal of Experimental Zoology 196 189-196

Mahi CA and Yanagimachi R (1978) Capacitation, acrosome reaction, and egg penetration by canine spermatozoa in a simple defined medium Gamete Research 1 101-109

Marston JH and Chang MC (1966) Morphology and timing of fertilisation and early cleavage in Mongolian gerbil and deer mouse Journal of Embryology and Experimental Morphology 15 169-191

Marston JH and Kelly WA (1968) Time relationship of spermatozoon penetration into the egg of the rhesus monkey Nature (London) 217 1073-1074

Martin RH (1985) Chromosomal abnormalities in human sperm Basic Life Sciences 36 91-102

Mattner PE (1963) Capacitation of ram spermatozoa and penetration of the ovine egg Nature (London) $199722-723$

Menkin MF and Rock J (1948) In vitro fertilisation and cleavage of human ovarian eggs American Journal of Obstetrics and Gynecology 55 440-452

Miyamoto H and Chang MC (1973a) In vitro fertilization of rat eggs Nature $24150-52$

Miyamoto $\mathbf{H}$ and Chang MC (1973b) Fertilization of rat eggs in vitro. Biology of Reproduction 9 384-393

Miyamoto H and Chang MC (1973c) The importance of serum albumin and metabolic intermediates for capacitation of spermatozoa and fertilization of mouse eggs in vitro. Journal of Reproduction and Fertility 32 193-205

Miyamoto H, Toyoda $\mathbf{Y}$ and Chang MC (1974) Effect of hydrogen-ion concentration on in vitro fertilization of mouse, golden hamster, and rat eggs Biology of Reproduction 10 487-493

Moricard R (1950) Penetration of the spermatozoon in vitro into the mammalian ovum oxydo potential level Nature(London) 165763

Moricard R and Bossu J (1949) Premieres etudes du passage du spermatozoide au travers de la membrane pellucide d'ovocytes de lapine fecondes 'in vitro'. Comptes Rendus de l'Academie de Medicine 33 659-665

Mortimer D (1994) Practical Laboratory Andrology Oxford University Press, New York

Mortimer D (2000) Sperm preparation methods Journal of Andrology 21 357-366

Mukherjee AB and Cohen MM (1970) Development of normal mice by in vitro fertilisation Nature (London) 228 472-473

Niemann H and Wrenzycki C (2000) Alterations of expression of developmentally important genes in preimplantation bovine embryos by in vitro culture conditions: implications for subsequent development Theriogenology 53 21-34

Noyes RW (1953) Fertilising capacity of spermatozoa Western Journal of Surgery, Obstetrics and Gynecology 61 342-349

Oehninger S, Franken D, Alexander N and Hodgen GD (1992) Hemizona assay and its impact on the identification and treatment of human sperm dysfunctions Andrologia 24 307-321

Oehninger S, Veeck L, Lanzendorf S, Maloney M, Toner J and Muasher S (1995) Intracytoplasmic sperm injection: achievement of high 
pregnancy rates in couples with severe male factor infertility is dependent primarily upon female and not male factors Fertility and Sterility 64 977-981

Ogawa S, Satoh K, Hamada M and Hashimoto H (1972) In vitro culture of rabbit ova fertilized by epididymal sperms in chemically defined media Nature 238 270-271

Palermo G, Joris H, Devroey P and van Steirteghem AC (1992) Pregnancies after intracytoplasmic injection of single spermatozoon into an oocyte Lancet 340 17-18

Palermo GD, Schlegel PN, Hariprashad JJ, Ergun B, Mielnik A, Zaninovic N, Veeck LL and Rosenwaks Z (1999) Fertilization and pregnancy outcome with intracytoplasmic sperm injection for azoospermic men Human Reproduction 14 741-748

Parrish JJ, Susko-Parrish J, Winer MA and First NL (1988) Capacitation of bovine sperm by heparin Biology of Reproduction 38 1171-1180

Parrish JJ, Susko-Parrish JL and First NL (1989) Capacitation of bovine sperm by heparin: inhibitory effect of glucose and role of intracellular pH Biology of Reproduction 41 683-699

Parrish JJ, Susko-Parrish JL, Handrow RR, Ax RL and First NL (1989) Effect of sulfated glycoconjugates on capacitation and the acrosome reaction of bovine and hamster spermatozoa Gamete Research 24 403-413

Pickworth S and Chang MC (1969) Fertilisation of Chinese hamster eggs in vitro. Journal of Reproduction and Fertility 19 371-374

Pikó L (1969) Gamete structure and sperm entry in mammals. In Fertilisation Vol. II pp 325-403 Eds CB Metz and A Monroy. Academic Press, New York

Pikó L and Tyler A (1964) Fine structural studies of sperm penetration in the rat Proceedings of the 5th International Congress on Animal Reproduction (Trento) 2 372-377

Pincus G (1936) The Eggs of Mammals Macmillan, New York

Pincus G (1939) The comparative behaviour of mammalian eggs in vivo and in vitro. IV. Development of fertilised and artificially activated rabbit eggs Journal of Experimental Zoology 82 65-129

Pincus G and Enzmann EV (1934) Can mammalian eggs undergo normal development in vitro? Proceedings National Academy of Sciences USA $20121-132$

Pincus G and Enzmann EV (1935) The comparative behaviour of mammalian eggs in vivo and in vitro. Journal of Experimental Medicine 62 665-675

Pincus G and Saunders B (1939) The comparative behaviour of mammalian eggs in vivo and in vitro. VI. The maturation of human ovarian ova Anatomical Record 75 537-542

Polge C (1969) Advances in reproductive physiology in pigs Journal of the Australian Institute of Agricultural Science September 147-153

Pope CE (2000) Embryo technology in conservation efforts for endangered felids Theriogenology 53 163-174

Pope CE, Gomez MC, Mikota SK and Dresser BL (2000) Development of in vitro produced African wildcat (Felis silvestris) embryos after cryopreservation and transfer into domestic cat recipients Biology of Reproduction $\mathbf{6 2}$ Supplement $\mathbf{1} 321$

Pope CE, Gomez MC, Davis AM, Harris RF, Mikota SK, Boyd EH and Dresser BL (2001) Oocyte retrieval, in vitro fertilization and embryo transfer in the caracal (Caracal caracal). Theriogenology 55397 (Abstract)

Rock J and Menkin MF (1944) In vitro fertilisation and cleavage of human ovarian eggs Science (New York) 100 105-106

Rockwell PL and Storey BT (2000) Kinetics of onset of mouse sperm acrosome reaction induced by solubilized zona pellucida: fluorimetric determination of loss of $\mathrm{pH}$ gradient between acrosomal lumen and medium monitored by dapoxyl (2-aminoethyl) sulfonamide and of intracellular $\mathrm{Ca}(2+)$ changes monitored by fluo-3 Molecular Reproduction and Development 55 335-349

Rogers BJ (1978) Mammalian sperm capacitation and fertilization in vitro: a critique of methodology Gamete Research 1 165-223

Rogers BJ and Perreault SD (1990) Importance of glycolysable substrates for in vitro capacitation of human spermatozoa Biology of Reproduction 43 1064-1069

Rogers BJ and Yanagimachi R (1975) Retardation of guinea pig sperm acrosome reaction by glucose: the possible importance of pyruvate and lactate metabolism in capacitation and the acrosome reaction Biology of Reproduction 13 568-575
Rogers BJ and Yanagimachi R (1976) Competitive effect of magnesium on the calcium-dependent acrosome reaction in guinea pig spermatozoa Biology of Reproduction 15 614-619

Rogers BJ, Chang L and Yanagimachi R (1979) Glucose effect on respiration: possible mechanism for capacitation in guinea pig spermatozoa Journal of Experimental Zoology 207 107-112

Rogers BJ, Van Campen H, Ueno M, Lambert H, Bronson R and Hale R (1979) Analysis of human spermatozoal fertilizing ability using zonafree ova Fertility and Sterility 32 664-670

Roth TL, Howard JG, Donoghue AM, Swanson WF and Wildt DE (1994a) Function and culture requirements of snow leopard (Panthera uncia) spermatozoa in vitro. Journal of Reproduction and Fertility 101 563-569

Roth TL, Swanson WF and Wildt DE (1994b) Developmental competence of domestic cat embryos fertilized in vivo versus in vitro. Biology of Reproduction 51 441-451

Rudak E, Jacobs PA and Yanagimachi R (1978) Direct analysis of the chromosome constitution of human spermatozoa Nature 274 911-913

Saacke RG and Almquist JO (1964) Ultrastructure of bovine spermatozoa. I. The head of normal ejaculated sperm American Journal of Anatomy 115 143-162

Saling PM and Storey BT (1979) Mouse gamete interactions during fertilization in vitro. Chlortetracycline as a fluorescent probe for the mouse sperm acrosome reaction Journal of Cell Biology 83 544-555

Schenk SL (1878) Das Säugetierei Künstlich befruchtet ausserhalb des Muttertieres Mittheilungen aus dem Embryolischen Institute der Kaiserlich-Königlichen Universität in Wien 1107

Schini SA and Bavister BD (1988) Two-cell block to development of cultured hamster embryos is caused by phosphate and glucose Biology of Reproduction 39 1183-1192

Shalgi R, Smith TT and Yanagimachi R (1992) A quantitative comparison of the passage of capacitated and uncapacitated hamster spermatozoa through the uterotubal junction Biology of Reproduction 46 419-424

Shettles LB (1953) Observations on human follicular and tubal ova American Journal of Obstetrics and Gynecology 66 235-247

Shivers CA and James JM (1970) Capacitation of frog sperm Nature (London) 227 183-184

Slavik T and Fulka J (1991) Pregnancies after transfer of sheep embryos produced from oocytes matured and fertilized in vitro. Folia Biologica (Praha) 37 94-100

Smith AU (1951) Fertilisation in vitro of the mammalian egg Biochemical Society Symposia (Cambridge) 7 3-10

Soupart P (1967) Studies on the hormonal control of rabbit sperm capacitation Journal of Reproduction and Fertility Supplement 2 49-62

Soupart P and Orgebin-Crist MC (1966) Capacitation of rabbit spermatozoa delayed in vivo by double ligation of uterine horn Journal of Experimental Zoology 163 311-318

*Steptoe PC and Edwards RG (1978) Birth after the reimplantation of a human embryo Lancet 2366

Steptoe PC, Edwards RG and Purdy JM (1971) Human blastocysts grown in culture Nature (London) 229 132-133

Stewart-Savage J and Bavister BD (1988) A cell surface block to polyspermy occurs in golden hamster eggs Developmental Biology 128 150-157

Strauss $\mathbf{F}$ (1956) Time and place of fertilisation of the golden hamster egg Journal of Embryology and Experimental Morphology 4 42-56

Suarez SS, Katz DF, Owen DH, Andrew JB and Powell RL (1991) Evidence for the function of hyperactivated motility in sperm Biology of Reproduction 44 375-381

Terada Y, Luetjens CM, Sutovsky P and Schatten G (2000) Atypical decondensation of the sperm nucleus, delayed replication of the male genome, and sex chromosome positioning following intracytoplasmic human sperm injection (ICSI) into golden hamster eggs: does ICSI itself introduce chromosomal anomalies? Fertility and Sterility 74 454-460

Thibault C (1949) L'oeuf des mammifieres son developpement parthenogenetique Annees de la Science Naturelle et de Zoologie et Biologie Animale 11 136-219

Thibault C and Dauzier L (1961) Analyse des conditions de la fecondation in vitro de l'oeuf de la lapine Annees de la Biologie Animale et de Biochimie et Biophysique 1 277-294 
Thibault C, Dauzier L and Wintenberger S (1954) Etude cytologique de la fecondation in vitro de l'oeuf de la lapine Comptes Rendue de la Societe de Biologie (Paris) 148 789-790

Tigyi G, Henschen A and Miledi R (1991) A factor that activates oscillatory chloride currents in Xenopus oocytes copurifies with a subfraction of serum albumin Journal of Biological Chemistry 266 $20602-20609$

Toyoda Y and Chang MC (1968) Sperm penetration of rat eggs in vitro after dissolution of zona pellucida by chymotrypsin Nature (London) 220 589-591

Toyoda Y and Chang MC (1974a) Fertilization of rat eggs in vitro by epididymal spermatozoa and the development of eggs following transfer Journal of Reproduction and Fertility 36 9-22

Toyoda Y and Chang MC (1974b) Capacitation of epididymal spermatozoa in a medium with high $\mathrm{K}-\mathrm{Na}$ ratio and cyclic AMP for the fertilization of rat eggs in vitro. Journal of Reproduction and Fertility 36 125-134

Toyoda YM, Yokoyama M and Hoshi T (1971a) Studies on the fertilization of mouse eggs in vitro. I. In vitro fertilization of eggs by fresh epididymal sperm Japanese Journal of Animal Reproduction 16 147-151

Toyoda YM, Yokoyama M and Hoshi T (1971b) Studies on the fertilization of mouse eggs in vitro. II. Effects of in vitro preincubation on time of sperm penetration of mouse eggs in vitro. Japanese Journal of Animal Reproduction 16 152-157

Travis AJ, Jorgez CJ, Merdiushev T, Jones BH, Dess DM, Diaz-Cueto L, Storey BT, Kopf GS and Moss SB (2001) Functional relationships between capacitation-dependent cell signaling and compartmentalized metabolic pathways in murine spermatozoa Journal of Biological Chemistry 276 7630-7636

Uehara T and Yanagimachi R (1977) Behavior of nuclei of testicular, caput and cauda epididymal spermatozoa injected into hamster eggs Biology of Reproduction 16 315-321

Vaidya RA, Bedford JM, Glass RH and Morris JM (1969) Evaluation of the removal of tetracycline fluorescence from spermatozoa as a test for capacitation in the rabbit Journal of Reproduction and Fertility 19 483-489

Vaidya RA, Glass RH, Dandekar P and Johnson K (1971) Decrease in the electrophoretic mobility of rabbit spermatozoa following intra-uterine incubation Journal of Reproduction and Fertility 24 299-301

van Steirteghem AC, Nagy Z, Joris H, Liu J, Staessen C, Smitz J, Wisanto A and Devroey $\mathbf{P}$ (1993) High fertilization and implantation rates after intracytoplasmic sperm injection Human Reproduction 8 1061-1066

Venge $\mathbf{O}$ (1953) Experiments on fertilisation of rabbit ova in vitro with subsequent transfer to alien does. In Mammalian Germ Cells Ciba Foundation Symposium pp 243-252 Ed. GEW Wolstenholme. Churchill Press, London

Vredenburgh-Wilberg WL and Parrish JJ (1995) Intracellular pH of bovine sperm increases during capacitation Molecular Reproduction and Development 40 490-502

Wakayama T, Whittingham DG and Yanagimachi R (1998) Production of normal offspring from mouse oocytes injected with spermatozoa cryopreserved with or without cryoprotection Journal of Reproduction and Fertility $11211-17$
Walton A and Hammond J (1928) Observations on ovulation in the rabbit British Journal of Experimental Biology 6 190-204

Ward CR and Storey BT (1984) Determination of the time course of capacitation in mouse spermatozoa using a chlortetracycline fluorescence assay Developmental Biology 104 287-296

Whittingham DG (1968) Fertilisation of mouse eggs in vitro. Nature (London) 220 592-593

Wolf DP and Hedrick JL (1971) A molecular approach to fertilisation. III. Development of a bioassay for sperm capacitation Developmental Biology 25 360-376

Yanagida K, Bedford JM and Yanagimachi R (1991) Cleavage of rabbit eggs after microsurgical injection of testicular spermatozoa Human Reproduction 6 277-279

Yanagimachi R (1966) Time and process of sperm penetration into hamster ova in vivo and in vitro. Journal of Reproduction and Fertility $\mathbf{1 1}$ 359-370

Yanagimachi R (1969a) In vitro capacitation of hamster spermatozoa by follicular fluid Journal of Reproduction and Fertility 18 275-286

Yanagimachi R (1969b) In vitro acrosome reaction and capacitation of golden hamster spermatozoa by bovine follicular fluid and its fractions Journal of Experimental Zoology 170 269-280

Yanagimachi R (1970) The movement of golden hamster spermatozoa before and after capacitation Journal of Reproduction and Fertility 23 193-196

Yanagimachi R (1972) Fertilization of guinea pig eggs in vitro. Anatomical Record 174 9-19

Yanagimachi R (1994) Mammalian fertilization. In The Physiology of Reproduction 2nd Edn pp 189-317 Eds E Knobil and JD Neill. Raven Press, New York

Yanagimachi R (1995) Is an animal model needed for intracytoplasmic sperm injection (ICSI) and other assisted reproduction technologies? Human Reproduction $102525-2526$

Yanagimachi R and Chang MC (1963) Fertilisation of hamster eggs in vitro. Nature (London) 200 281-282

*Yanagimachi R and Chang MC (1964) In vitro fertilisation of golden hamster ova Journal of Experimental Zoology 156 361-376

Yanagimachi R and Mahi CA (1976) The sperm acrosome reaction and fertilization in the guinea-pig: a study in vivo. Journal of Reproduction and Fertility 46 49-54

Yanagimachi R, Yanagimachi H and Rogers BJ (1976) The use of zona-free animal ova as a test-system for the assessment of the fertilizing capacity of human spermatozoa Biology of Reproduction 15 471-476

Yanagimachi R, Lopata A, Odom CB, Bronson RA, Mahi CA and Nicolson GL (1979) Retention of biologic characteristics of zona pellucida in highly concentrated salt solution: the use of salt-stored eggs for assessing the fertilizing capacity of spermatozoa Fertility and Sterility 31 562-574

Yoshimatsu N, Yanagimachi R and Lopata A (1988) Zonae pellucidae of salt-stored hamster and human eggs: their penetrability by homologous and heterologous spermatozoa Gamete Research 21 115-126

Zamboni L (1970) Ultrastructure of mammalian oocytes and ova Biology of Reproduction Supplement 2 44-63 